\title{
Review
}

\section{Melatonin as an antioxidant: biochemical mechanisms and pathophysiological implications in humans}

\author{
Russel J. Reiter ${ }^{1 凶}$, Dun-xian Tan ${ }^{1}$, Juan C. Mayo ${ }^{1}$, Rosa M. Sainz, Josefa Leon ${ }^{1}$ \\ and Zbigniew Czarnocki ${ }^{2}$ \\ ${ }^{1}$ Department of Cellular and Structural Biology, University of Texas Health Science Center, \\ San Antonio, Texas, U.S.A.; ${ }^{2}$ Department of Chemistry, Warsaw University, Warszawa, \\ Poland
}

Received: 17 September, 2003; revised: 17 October, 2003; accepted: 21 October, 2003

Key words: antioxidant, antioxidant enzymes, free radicals, melatonin, neurodegeneration, respiratory distress, sepsis

\begin{abstract}
This brief resume enumerates the multiple actions of melatonin as an antioxidant. This indoleamine is produced in the vertebrate pineal gland, the retina and possibly some other organs. Additionally, however, it is found in invertebrates, bacteria, unicellular organisms as well as in plants, all of which do not have a pineal gland. Melatonin's functions as an antioxidant include: a), direct free radical scavenging, b), stimulation of antioxidative enzymes, c), increasing the efficiency of mitochondrial oxidative phosphorylation and reducing electron leakage (thereby lowering free radical generation), and 3), augmenting the efficiency of other antioxidants. There may be other functions of melatonin, yet undiscovered, which enhance its ability to protect against molecular damage by oxygen and nitrogen-based toxic reactants. Numerous in vitro and in vivo studies have documented the ability of both physiological and pharmacological concentrations to melatonin to protect against free radical destruction. Furthermore, clinical tests utilizing melatonin have proven highly successful; because of the positive outcomes of these studies, melatonin's use in disease states and processes where free radical damage is involved should be increased.
\end{abstract}

\footnotetext{
${ }^{凶}$ Corresponding author: Russel J. Reiter, Ph.D., Department of Cellular and Structural Biology, Mail Code 7762, The University of Texas Health Science Center, 7703 Floyd Curl Drive, San Antonio, TX 78229-3900 U.S.A.; phone: 210/567-3859; fax: 210/567-6948; e-mail: Reiter@UTHSCSA.EDU Abbreviations: AD, Alzheimer's disease; AFMK, $N^{1}$-acetyl- $N^{2}$-formyl-5-methoxykynuramine; CAT, catalase; DMPO, 5,5-dimethylpyrolidine oxide; ETC, electron transport chain; G6PD, glucose-6-phosphate dehydrogenase; GPx, glutathione peroxidase; GRd, glutathione reductase; LOO, peroxyl radical; MPTP, 1-methyl-4-phenylpyridinium; RDS, respiratory distress syndrome; RNS, reactive nitrogen species; ROS, recative oxygen species; SOD, superoxide dismutase; t-BHP, $t$-butyl-hydroperoxide.
} 
$N$-Acetyl-5-methoxytryptamine, commonly known as melatonin (Fig. 1), is a synthetic product of the vertebrate pineal gland as well as of other select organs. The biochemical pathway concerned with the synthesis of melatonin has been well described as have been the neural mechanisms governing pineal melatonin production (Reiter, 1991). The indoleamine was initially found to function as a mediator of circannual reproductive rhythms (Reiter, 1980) as well as of circadian cycles (Kennaway \& Wright, 2002). Subsequently, however, melatonin was shown to have significantly broader actions including oncostatic effects (Blask et al., 2002), immune system stimulation (Guerrero \& Reiter, 2002) and anti-inflammatory functions (Cuzzocrea \& Reiter, 2002).

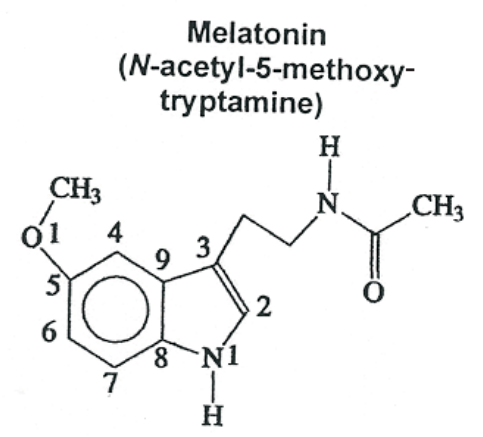

Figure 1. Molecular structure of the antioxidant melatonin.

This molecule was discovered to be a direct free radical scavenger roughly a decade ago and subsequently there has been a vast amount of research documenting its potent and diverse antioxidant capabilities.

Even more recently, and somewhat unexpectedly, melatonin was identified as a powerful direct free radical scavenger (Tan et al., 2002) and indirect antioxidant (Reiter et al., 2000c; Rodriquez et al., 2004). What seems particularly unusual is the high efficacy of melatonin as a protector against reactive oxygen (ROS) and reactive nitrogen species (RNS). This field of research has witnessed an explosive expansion in the last decade and whereas all of the mechanisms of melatonin's effects as an executioner of free radicals and related products have not yet been identified, there is no doubt concerning its ability to restrain the molecular damage resulting from toxic oxygen and nitrogen-based reactants (Acuña-Castroviejo et al., 2002; Reiter et al., 2002b). This review summarizes some of the mechanisms of melatonin's protective actions as well as documents that it significantly reduces oxidative stress at many levels. It is noted, however, that this brief resume cannot do justice to the massive number of reports that have been published on these subjects and the reader is urged to consult other reviews for additional details and information (Hardeland et al., 1995; Reiter et al., 2000b, 2001; Tan et al., 2002; 2003b).

\section{DIRECT ANTIOXIDANT ACTIONS OF MELATONIN}

Melatonin seems to function via a number of means to reduce oxidative stress. Thus, the experimental evidence supports its actions as a direct free radical scavenger (Hardeland et al., 1993; 1995; Allegra et al., 2003), as an indirect antioxidant when stimulating antioxidant enzymes (Reiter et al., 2000c; Rodriquez et al., 2004), its stimulation of the synthesis of glutathione (an essential intracellular antioxidant) (Urata et al., 1999), its ability to augment the activities of other antioxidants (or vice versa) (Gitto et al., 2001a), its protection of antioxidative enzymes from oxidative damage (Mayo et al., 2002; 2003), and its ability to increase the efficiency of mitochondrial electron transport chain (ETC) thereby lowering electron leakage and reducing free radical generation (Acuña-Castroviejo et al., 2002; Okatani et al., 2003a). While melatonin has proven highly effective in lowering molecular damage under conditions of elevated oxidative stress (Reiter, 1998; Reiter \& Tan, 2003), the contribution of each of the above-mentioned processes to the ability of this indole to restrain the resulting molecular mutilation that accompanies exag- 
gerated free radical generation remains unknown.

\section{Melatonin as a direct scavenger of oxygen- based free radicals and related species}

There is now a vast literature documenting melatonin's interaction with both ROS and RNS (Reiter et al., 2001; Poeggeler et al.,
1997; Bandyopadhyay et al., 2002; Brömme et al., 2002; Li et al., 2002) and, furthermore, a potential product of that interaction has been identified to be cyclic 3-hydroxymelatonin (Tan et al., 1998). In the proposed scheme, each molecule of melatonin scavenges two - $\mathrm{OH}$; this study also showed that cyclic 3-hydroxymelatonin is excreted in the urine (human and rat) and the quantity of this by-

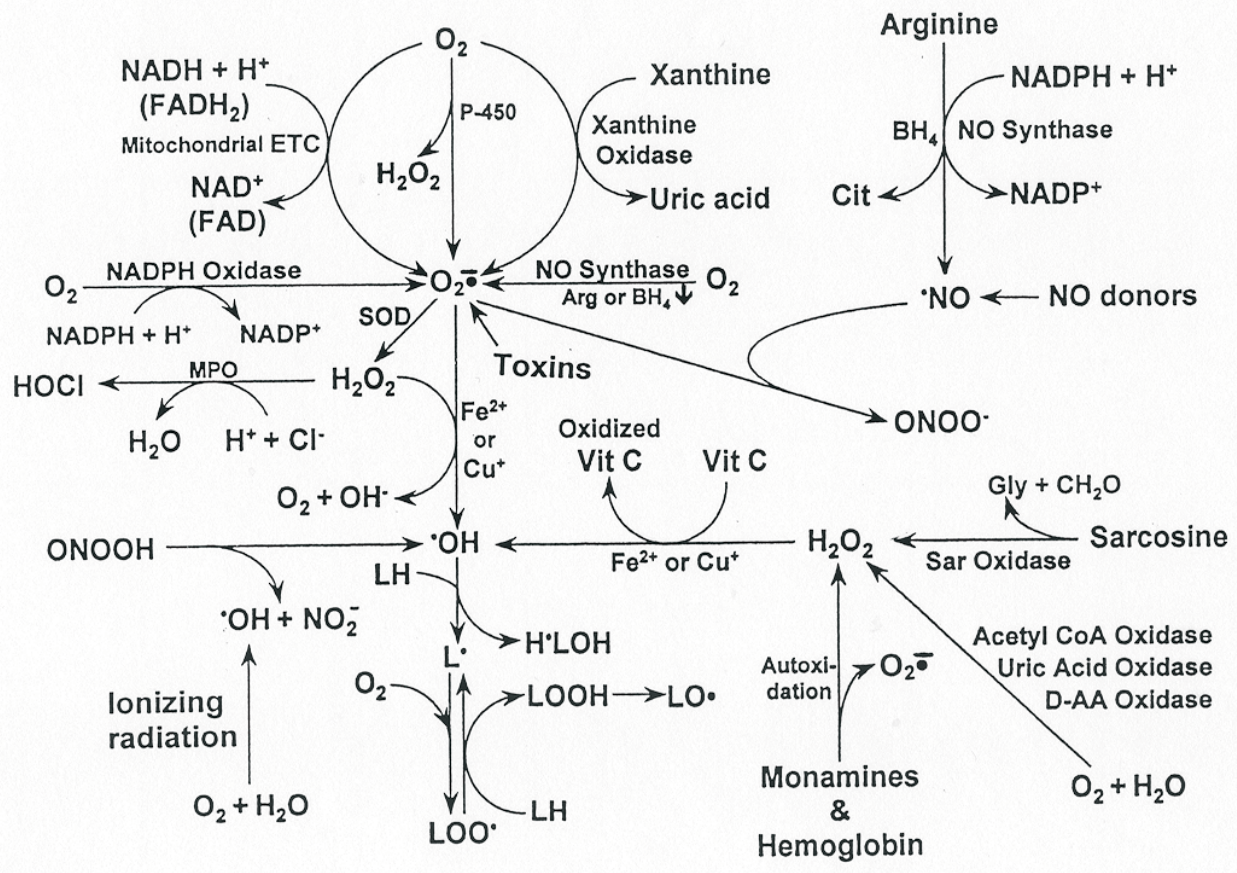

Figure 2. Oxygen and nitrogen-based free radicals and associated reactants that are generated in cells by various processes.

Free radicals are defined as molecules that have an unpaired electron in their valence orbital. Free radicals and the related reactants are not equally toxic. It is generally conceded that the most reactive, and therefore damaging, products are the oxygen-based hydroxyl radical $(\cdot \mathrm{OH})$ and the nitrogen-based peroxynitrite anion $\left(\mathrm{ONOO}^{-}\right)$. Arg, L-arginine; $\mathrm{BH}_{4}$, 5,6,7,8-tetrahydro-L-biopterin; Cit, L-citruline; ETC, electron transport chain; FAD, flavin adenine dinucleotide (oxidized); $\mathrm{FADH}_{2}$, flavin adenine dinucleotide (reduced); Gly, glycine; MOP, myloperoxidase; $\mathrm{NAD}^{+}$, nicotinamide adenine dinucleotide (oxidized); NADH, nicotinamide adenine dinucleotide (reduced); P-450, cytochrome P-450.

2002; Tan et al., 2002; Allegra et al., 2003). The initial evidence illustrating melatonin's ability to neutralize the highly toxic hydroxyl radical $(\cdot \mathrm{OH})$ (Fig. 2 ) appeared roughly 10 years ago (Tan et al., 1993). Since then, numerous reports have appeared which confirm this action of melatonin (Poeggeler et al., 1994; Hardeland et al., 1995; Matuszak et al., product is proportional to the amount of melatonin administered to an animal and to the degree of oxidative stress the animal has experienced. The findings also indicate that cyclic 3 -hydroxymelatonin is a footprint molecule that appears in the urine and that it is an index of in vivo $\cdot \mathrm{OH}$ scavenging by melatonin. Finally, cyclic 3-hydroxymelatonin it- 
self has free radical scavenging activity (Tan et al., 2003b; Lopez-Burillo et al., 2003).

Stasica and co-workers (2000), using a computational approach, determined the most likely probable site on the indole ring of melatonin that may bind a $\cdot \mathrm{OH}$; the $\mathrm{C} 2$ carbon was proposed as the likely site of attack. Additional details concerning the structural properties of melatonin that make it an efficient scavenger of the $\cdot \mathrm{OH}$ as well as the potential reactions of the indole as a radical scavenger are reviewed by Tan and colleagues (2002).

Hydrogen peroxide $\left(\mathrm{H}_{2} \mathrm{O}_{2}\right)$, a non-radical ROS, is generated in vivo by several enzyme systems and, additionally, it is produced intracellularly by the dismutation of the superoxide anion radical $\left(\mathrm{O}_{2}{ }^{-}\right)$(Fig. 2). In vivo, $\mathrm{H}_{2} \mathrm{O}_{2}$ is a weak oxidizing and reducing agent. Also, no electric charge allows $\mathrm{H}_{2} \mathrm{O}_{2}$ to traverse cell membranes and is therefore accessible to sites significantly removed from its point of generation. Although $\mathrm{H}_{2} \mathrm{O}_{2}$ is weakly reactive, its major toxicity derives from its conversion to the highly toxic $\cdot \mathrm{OH}$ via the Fenton or Haber-Weiss reactions.

Melatonin as a scavenger of $\mathrm{H}_{2} \mathrm{O}_{2}$ in a pure chemical system was initially documented by Tan et al. (2000). A mechanism of the oxidation of melatonin by $\mathrm{H}_{2} \mathrm{O}_{2}$ was suggested on the basis of the major resulting metabolite, i.e., $N^{1}$-acetyl- $N^{2}$-formyl-5-methoxykynuramine (AFMK). AFMK was confirmed using electron ionization mass spectrometry and proton and carbon nuclear magnetic resonance. Whether intracellular melatonin neutralizes $\mathrm{H}_{2} \mathrm{O}_{2}$ in a manner as described by Tan et al. (2000) is unknown. If it does, it would act like the $\mathrm{H}_{2} \mathrm{O}_{2}$-metabolizing enzymes, i.e., glutathione peroxidase (GSH-Px) and catalase (CAT), in the removal of this oxidizing agent and, importantly, reduce the generation of the $\cdot \mathrm{OH}$. That AFMK is a byproduct of the interaction of melatonin with $\mathrm{H}_{2} \mathrm{O}_{2}$ has been reported by others as well including under in vivo conditions (Burkhardt et al., 2001; Carampin et al., 2003; Rozov et al., 2003).
One recent report questioned whether melatonin interacts directly with $\mathrm{H}_{2} \mathrm{O}_{2}$ (Fowler et al., 2003). Why this group failed to document what other reports found is not apparent but could be related to the fact they tested a single dose of melatonin.

Recently, significant attention has been focused on AFMK as a scavenger of oxygen-based reactants as well. Cyclic voltametry has shown that AFMK is capable of donating two electrons; furthermore, the kynuramine reduces damage to DNA and lipids in a high free radical environment and lowers neuronal death when these cells are exposed to either $\mathrm{H}_{2} \mathrm{O}_{2}$, glutamate or amyloid $\beta_{25-35}$ (each of these is known to generate free radicals) (Tan et al., 2001). This indicates that not only the parent molecule, i.e., melatonin, but also the resulting products, i.e., cyclic 3-hydroxymelatonin and AFMK, may also function as scavengers of toxic reactants. This cascade of scavenging actions may be one reason accounting for the unexpectedly high efficacy of melatonin in reducing free radical damage in vivo. Finally, another product, $N$-acetyl-5-methoxykynuramine (AMK), is likewise capable of neutralizing some oxygen-based reactants (Tan et al., 2002; Ressmeyer et al., 2003) as is the chief hepatic enzymatic metabolite of melatonin, 6-hydroxymelatonin (Qi et al., 2000; Hara et al., 2001).

$\mathrm{O}_{2}{ }^{\cdot-}$ (Fig. 2) is generated during respiration in mitochondria when electrons leak from the ETC and during the respiratory burst of phagocytic cells. Relative to the $\cdot \mathrm{OH}, \mathrm{O}_{2}{ }^{\cdot-}$ has low toxicity but it rapidly couples with nitric oxide $(\mathrm{NO} \cdot)$ to produce a non-radical nitrogen-based reactant, the peroxynitrite anion $\left(\mathrm{ONOO}^{-}\right)$(Fig. 2); this product is considered to be almost as damaging as is the $\cdot \mathrm{OH}$. In addition to its inherent toxicity, $\mathrm{ONOO}^{-}$ via peroxynitrous acid ( $\mathrm{ONOOH})$ may be metabolized to the $\cdot \mathrm{OH}$ in vivo.

The efficacy of melatonin in neutralizing the $\mathrm{O}_{2}{ }^{-}$is only poorly defined. Melatonin reportedly scavenges this reactant in a pure chemical system where a hypoxanthine/ xan- 
thine system was used to generate the $\mathrm{O}_{2}{ }^{\cdot-}$ (Marshall et al., 1996); the ability of melatonin to quench the $\mathrm{O}_{2}{ }^{-}{ }^{-}$is also supported by evidence that melatonin modestly diminished the electron spin resonance (ESR) signal produced by the adduct, 5,5-dimethylpyrroline oxide (DMPO)- $\mathrm{O}_{2}{ }^{-}$(Zang et al., 1998). However, the role, if any, of melatonin in neutralizing the $\mathrm{O}_{2}{ }^{-}$is unclear, particularly in vivo.

Macromolecular damage in vivo is also a consequence of singlet oxygen $\left({ }^{1} \mathrm{O}_{2}\right)$, an energy-rich form of oxygen; ${ }^{1} \mathrm{O}_{2}$ is usually produced in photosensitizing reactions of a variety of substrates including dyes and biological pigments. Poeggeler and co-workers (1996) were the first to show that melatonin neutralized ${ }^{1} \mathrm{O}_{2}$, during which AFMK was generated. This quenching ability of melatonin was confirmed by Zang et al. (1998) and by Roberts and colleagues (2000). That AFMK is the product formed when melatonin is oxidized by ${ }^{1} \mathrm{O}_{2}$ has been confirmed (De Almeida et al., 2003). In light of these findings, it appears that AFMK is a product common to several interactions of melatonin with oxygen-based reactants.

The evidence that melatonin functions as a chain breaking antioxidant by scavenging the peroxyl radical (LOO·) remains problematic. The first reports on this subject placed melatonin among the very best scavengers in terms of its ability to neutralize the LOO. (Fig. 2); thus, the claim was made that melatonin is twice as effective as vitamin $\mathrm{E}$, the primier chain breaking antioxidant, in interfering with the propagation of lipid peroxidation (Pieri et al., 1994; 1995). These reports, however, have not been universally confirmed. Using a markedly different system to perform their tests, Livrea and co-workers (1997) also analyzed the ability of melatonin in terms of its chain breaking activity. Using either non-peroxidable unilamellar dimirystoyl phosphatidycholine liposomes or peroxidable soybean phosphatidylcholine liposomes, this group reported that mela- tonin was not a particularly effective chain breaking antioxidant. The data accumulated by Livrea et al. (1997) are consistent with those of Antunes and colleagues (1999) who thoroughly evaluated the lipoperoxyl-trapping efficiency of melatonin and concluded that it had limited ability to neutralize directly the $\mathrm{LOO} \cdot$. Given that melatonin is a heterocyclic aromatic amine, this group noted that molecules containing an $\mathrm{NH}$ group in a 5-membered pyrrole and carbazole ring do not typically function as highly effective chain breaking antioxidants.

Despite the controversy regarding the ability of melatonin to interact with the $\mathrm{LOO} \cdot$, in vivo melatonin has consistently been found to be highly efficient in limiting the peroxidation of lipids (Reiter et al., 1998). Curtailing the progress of self-propagating lipid breakdown by melatonin may be a result of its ability to scavenge the initiating agents, e.g., $\cdot \mathrm{OH}, \mathrm{ONOO}^{-}$, etc., rather than being due to its apparent limited capability as a direct LOO - scavenger, i.e., to function as a chain breaking antioxidant.

Due to the electron-deficient nature of halide ions, haloperoxyl radicals are significantly more reactive than the alkylperoxyl radical; accordingly, the trichloromethylperoxyl radical $\left(\mathrm{CCl}_{3} \mathrm{OO} \cdot\right)$ was found to be potently trapped by melatonin (Marshall et al., 1996). In a pulse radiolysis study, this finding was also reported by Mahal and co-workers (1999). This latter group also showed, like Scaiano (1995), that melatonin traps the tert-butoxyl radical.

Hypochlorous acid (HOCl) formation is catalyzed by myloperoxidase (MPO) in activated neutrophils (Fig. 2). $\mathrm{HOCl}$ is a powerful oxidizing agent and it damages a wide variety of biomolecules. Presumably by electron donation, Dellegar et al. (1999) reported that melatonin detoxifies HOCl. In the process, melatonin is theoretically converted to the melatoninyl cation radical which could scavenge another radical. This melatonin radical intermediate has also been proposed in other 
scavenging actions of the indoleamine (Tan et al., 1993; 1998).

\section{Melatonin as a direct scavenger of nitro- gen-based free radicals and related species}

NO · (nitrogen monoxide), a molecule widely produced in mammals where it has a variety of beneficial functions is a rather weak free radical. NO is involved in a number of inflammatory processes that can lead to extensive tissue injury. Additionally, much of the toxicity of $\mathrm{NO}$ - may be a consequence of its coupling with $\mathrm{O}_{2}{ }^{-}$- which results in the formation of the highly reactive $\mathrm{ONOO}^{-}$(Fig. 2).

That melatonin detoxifies $\mathrm{NO} \cdot$ has been reported by several groups (Mahal et al., 1999; Noda et al., 1999; Blanchard et al., 2000). The latter group, however, showed that melatonin interacts with $\mathrm{NO}$ - only in the presence of molecular oxygen, a finding suggesting that melatonin may in fact react with a molecule derived from nitric oxide, possibly $\mathrm{ONOO}^{-}$. The requirement for $\mathrm{O}_{2}$ in the reaction of melatonin with $\mathrm{NO}$. was confirmed by Turjanski et al. (2000a; 2000b). The chief product of the melatonin/ $\mathrm{NO} \cdot$ reaction is reportedly $N$-nitrosomelatonin. Semiempirical AM1 computations are consistent with the nitrosation of melatonin by $\mathrm{NO} \cdot / \mathrm{O}_{2}$ (Turjanski et al., 2000c).

The coupling of two relatively unreactive species, i.e., $\mathrm{NO} \cdot$ and $\mathrm{O}_{2}{ }^{-}$, generates the potently oxidizing $\mathrm{ONOO}^{-}$(Fig. 2); this combination reaction has a very high rate constant $\left(5.0 \times 10^{9} \mathrm{M}^{-1} \mathrm{~s}^{-1}\right)$. The toxicity of peroxynitrite could relate to any of three reactive species, i.e., ground state peroxynitrous acid $(\mathrm{ONOOH})$, the activated form of the acid $\left(\mathrm{ONOOH}^{*}\right)$ as well as to its conjugated base $\left(\mathrm{ONOO}^{-}\right)$. Zhang and colleagues $(1998 ; 1999)$ documented that melatonin is a substrate for peroxynitrite. Melatonin was shown to react with $\mathrm{ONOO}^{-}$with first-order kinetics; however, the rate constant for the reaction of melatonin with $\mathrm{ONOOH}$ was considerably higher (a reaction unimportant at physiologi- cal pH). Blanchard et al. (2000) also found that melatonin interacted with $\mathrm{ONOO}^{-}$but with the formation of different products than those reported by Zhang et al. (1998; 1999). These differences cannot currently be explained.

\section{INDIRECT ANTIOXIDANT ACTIONS OF MELATONIN}

Besides its ability to directly scavenge oxygen and nitrogen-based reactants, melatonin has a number of indirect means by which it may reduce oxidative stress. The relative importance of the direct and indirect antioxidative processes of melatonin in vivo remain unknown.

\section{Melatonin stimulation of antioxidative enzymes}

Antioxidative enzymes provide a major defense mechanism against free radical damage either by metabolizing them to less reactive species or to non-toxic byproducts (Fig. 3). The important antioxidative enzymes that have been investigated relative to melatonin are the superoxide dismutases (SOD), both MnSOD and CuZnSOD, catalase (CAT), glutathione peroxidase (GPx), glutathione reductase (GRd) and glucose-6-phosphate dehydrogenase (G6PD) (Reiter et al., 2000c; Mayo et al., 2002; Rodriquez et al., 2004).

The initial reports documenting melatonin's stimulatory effect on GPx appeared almost 10 years ago when it was shown that pharmacological doses of melatonin given to rats (Barlow-Walden et al., 1995) and chicks (Pablos et al., 1995) in vivo resulted in a marked augmentation in the activity of this enzyme. GPx reduces free radical damage because it metabolizes $\mathrm{H}_{2} \mathrm{O}_{2}$ (and other peroxides) to water; in the process, however, glutathione (GSH) is oxidized to its disulfide, GSSG (Fig. 3). GSSG is then quickly reduced back to GSH by GRd, an enzyme which has 
also been shown to be stimulated by melatonin (Pablos et al., 1998). The recycling of GSH may well be a major action of melatonin in curtailing oxidative stress. The ability of melatonin to regulate the GSH/GSSG balance by modulating enzyme activities appears to involve an action of melatonin at a nuclear binding site (Pablos et al., 1997). The other GSH metabolizing enzyme, i.e., CAT, also increases its activity in response to melatonin (Naidu et al., 2003).

Subsequent studies showed that the stimula- ties of these enzymes in a number of tissues is extinguished if chicks are kept under constant light; light exposure at night, of course, prevents the nocturnal rise in physiological melatonin concentrations which, because of the loss of this stimulatory signal, prevents the activities of GPx and GRd from rising.

GRd requires the co-factor NADPH which is generated by the antioxidative enzyme G6PD (Fig. 3). Although the amount of data is limited, there is one report claiming that melatonin also stimulates G6PD (Pierrefiche

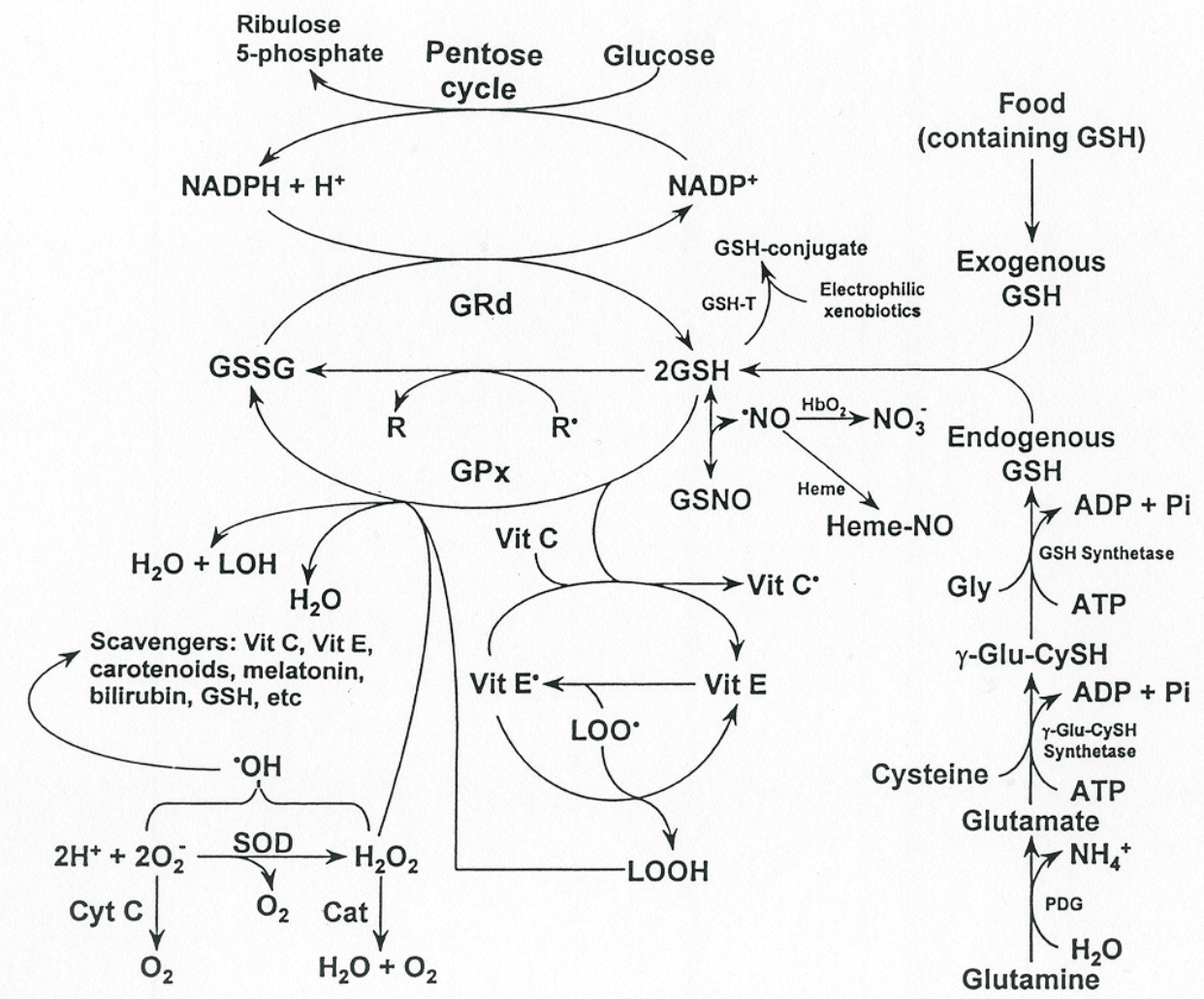

Figure 3. Free radicals and other reactants are enzymatically removed from cells by a series of antioxidative enzymes.

Melatonin stimulates the activity of several of these as summarized in the text. Melatonin also promotes the production of glutathione, an important intracellular antioxidant. Arg, L-arginine; $\mathrm{GH}_{4}$, 5,6,7,8-tetrahydro-biopterin; Cat, catalase; Cyt c, cytochrome c; GSSG, glutathione (oxidized; glutathione disulfide); GSH, glutathione (reduced); GPx, glutathione peroxidase; GRd, glutathione reductase; GSH-T, glutathione $S$-transferase; GSNO, nitrosylated glutathione; $\mathrm{HbO}_{2}$, oxyhemoglobin; PDG, phosphate-dependent glutaminase; SOD, superoxide dismutase.

tion of the activities of GPx and GRd is achieved with physiological levels of melatonin. Thus, Pablos et al. (1998) observed that the normal nighttime rise in the activi-
\& Laborit, 1995). This would be important in GSH recycling since NADPH is a necessary cofactor for G6PD. 
Subsequent to this early series of studies, numerous reports have confirmed and extended the evidence concerning the promotional effects of melatonin on the antioxidative enzymes (Rodriquez et al., 2004) including, not only GPx and GRd but SOD as well. Furthermore, due to the ease with which it crosses the placenta, melatonin, when administered to pregnant rats, results in a rise in GPx and SOD activities in the brain of the fetuses (Okatani et al., 2000). Also, in the human chorion melatonin has been found to increase GPx activity (Okatani et al., 2001).

In addition to estimating enzyme activities, gene expression for antioxidative enzymes have been studied following melatonin administration. For example, Mayo et al. (2002) found that the depressions in gene expression for neural GPx, CuZnSOD and MnSOD that occurred after treatment of rats with the neurotoxin 6-hydroxydopamine were prevented by melatonin. Similarly, others (Kotler et al., 1998; Antolin et al., 2002) have also observed that melatonin enhances gene expression for antioxidative enzymes either under basal conditions or after their inhibition by neurotoxic agents. While the direct free radical scavenging properties of melatonin are independent of any receptor for the indole, its ability to alter the activity of antioxidative enzymes likely requires an interaction of melatonin with either membrane or nuclear receptors.

While melatonin clearly functions as a direct free radical scavenger and indirectly reduces oxidative stress via the stimulation of antioxidative enzymes, the relative importance of each of these processes in reducing tissue damage due to free radicals in an unresolved issue. The high efficacy of melatonin in preventing oxidative mutilation of essential biomolecules suggests that both mechanisms must be important and, in fact, other processes, as summarized below, may likewise contribute to melatonin's unexpectedly strong antioxidative capabilities.

\section{Melatonin stimulation of glutathione synthesis}

GSH is very abundant intracellular free radical scavenger and antioxidant (Fig. 3). A single report has shown that melatonin stimulates its rate limiting enzyme, $\gamma$-glutamylcysteine synthase, thereby increasing intracellular GSH concentrations (Urata et al., 1999). This action of melatonin, unlike the direct free radical scavenging function of the indoleamine, is likely mediated by specific receptors. The stimulation of GSH synthesis by melatonin could be a major antioxidative action of melatonin. Considering the potential importance of the findings of Urata and co-workers (1999), it is in need of confirmation particularly in vivo and in a variety of cell types.

\section{Synergistic actions of melatonin with clas- sic antioxidants}

According to Gitto and co-workers (2001a), under in vitro conditions and using end products of lipid peroxidation as an indices of free radical damage, melatonin augments the protective actions of vitamin $\mathrm{E}$, vitamin $\mathrm{C}$ and GSH against free radical-mediated oxidation of polyunsaturated fatty fats. The clear implication, and the conclusion reached by the authors, is that combinations of melatonin with other antioxidants clearly increase their efficacy. The mechanism of the synergy remains unknown and confirmation of these findings, particularly in vivo, is important. When compared under conditions of high oxidative stress in vivo, melatonin has proven superior to vitamins $\mathrm{C}$ and $\mathrm{E}$ in reducing oxidative damage (Tan et al., 2002).

\section{Actions of melatonin at the level of the mitochondria}

Mitochondria are a major source of free radicals and as a consequence these subcellular organelles are exposed to extensive oxidative abuse. The inner mitochondrial membrane is the site of the ETC (Fig. 4), a system of 
oxido-reductant protein complexes (complexes I, II, III and IV). In aerobic cells, mitochondrial oxidative phosphorylation (OXPHOS) is responsible for an estimated $90-95 \%$ of the total ATP generated by cells. Deficiencies in the ETC can lead to the leakage of electrons which thereafter form free radicals and other toxic reactants which results in molecular damage in mitochondria; this damage culminates in and contributes to what are referred to as mitochondria-related diseases (Acuña-Castroviejo et al., 2002).

That melatonin has important actions at the level of mitochondria is suggested by a number of observations: a), melatonin is an efficient scavenger of ROS/RNS which are abun- trations in mitochondria than elsewhere in the cell and higher than serum concentrations of melatonin (Acuña-Castroviejo et al., 2002).

Long term melatonin administration has been reported to increase the number of mitochondria in cells (Decker \& Quay, 1982) while experiments with radioactive melatonin suggests mitochondrial binding sites for the indole (Poon \& Pang, 1992). Additionally, melatonin was shown to inhibit NADPH-dependent lipid peroxidation in human placental mitochondria (Milczarek et al., 2000), to protect the fetal rat brain against oxidant-mediated mitochondrial damage (Wakatsuki et al., 2001) and to stimulate mitochondrial res-

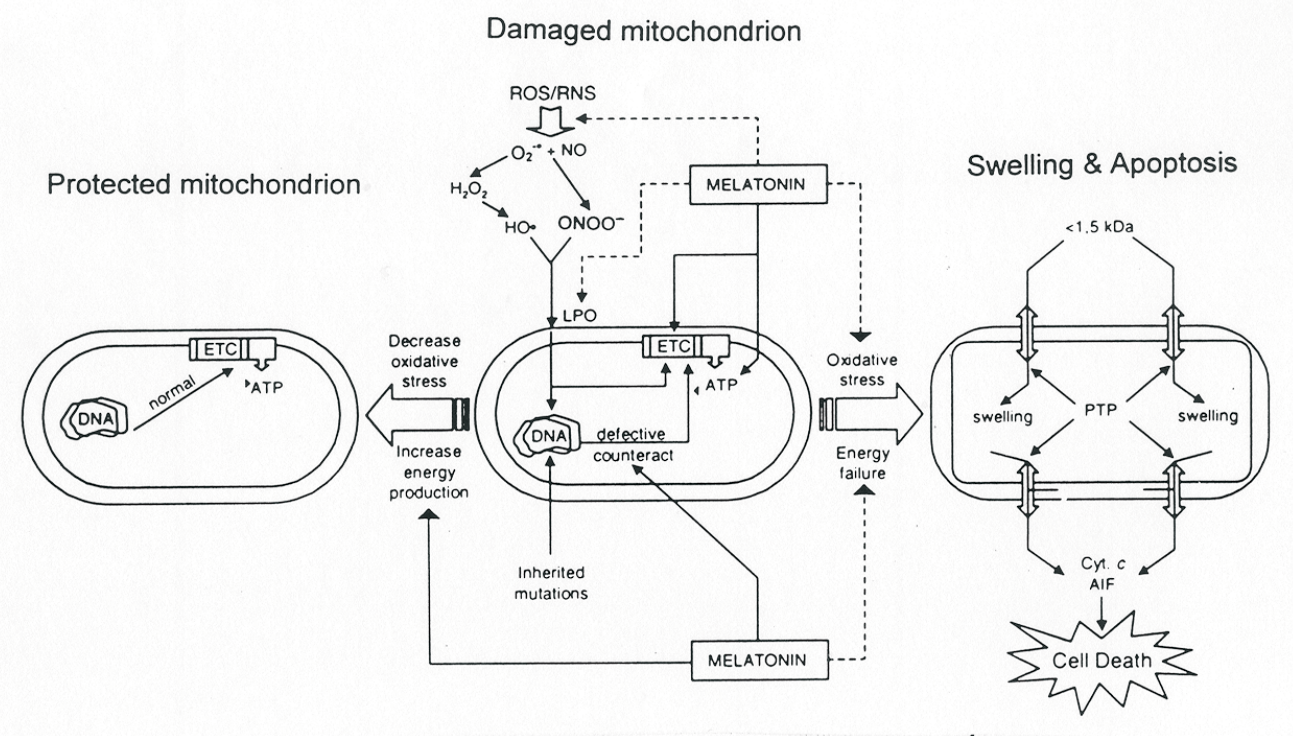

Figure 4. Actions of melatonin at the mitochondrial level increase its efficiency as an antioxidant by reducing free radical generation and increasing ATP production.

These actions of melatonin are summarized in the text. Cyt c, cytochrome $c$; RNS, reactive nitrogen species; ROS, reactive oxygen species; ETC, electron transport chain.

dantly produced in mitochondria; b), although mitochondria are incapable of GSH synthesis (they take it up from the cytosol), they do possess GPx and GRd for GSH cycling, both enzymes of which are stimulated by melatonin; c), melatonin has been shown to have antiapoptotic effects, with the apoptotic signals originating in mitochondria; d), melatonin may be in higher concen- piration in the brain and liver of senescence-accelerated mice (Okatani et al., 2002a; 2002b; 2003a; 2003b).

The first tests of melatonin in reference to mitochondrial physiology were performed in vivo. In these studies, melatonin was shown to significantly increase hepatic and brain complex I and complex IV activities of the mitochondrial ETC (Martin et al., 2000a). Fur- 
thermore, it was shown that melatonin reverses the inhibitory effect of 1-methyl-4phenylpyridinium (MPTP) (Absi et al., 2000) and ruthenium red (Martin et al., 2000a) on the activities of these complexes.

In in vitro experiments, Martin et al. (2000b) documented that when oxidative damage was induced in mitochondria by incubating them with $t$-butyl hydroperoxide (t-BHP), the effect was prevented with a $100 \mathrm{nM}$ concentration of melatonin; conversely, neither the addition of $\mathrm{N}$-acetylcysteine, vitamin $\mathrm{E}$ nor vitamin $\mathrm{C}$ protected mitochondria against t-BHP toxicity. Melatonin's stimulation of complexes I and IV activities were dose-dependent. Finally, melatonin reduces cyanide toxicity at the level of mitochondria as well (Yamamoto \& Yang, 1996) These actions of melatonin would be very important physiologically considering ETC efficiency is coupled to OXPHOS. Subsequent studies, in fact, reported that ATP production is also elevated when mitochondria are treated with melatonin (Martin et al., 2001). As an energy source, ATP is critical to the cell for virtually all functions including the repair of oxidatively-damaged molecules. Thus, besides protecting molecules from damage due to ROS and RNS, once molecules are damaged melatonin may indirectly hasten their repair. This is an area of melatonin research that awaits further experimentation. Also, increasing the efficiency of the ETC theoretically, at least, may reduce electron leakage and free radical production. The actions of melatonin at the mitochondrial are summarized in Fig. 4.

\section{PATHOPHYSIOLOGICAL EVIDENCE OF THE ANTIOXIDANT FUNCTIONS OF MELATONIN IN HUMANS}

Antioxidants have attracted a great deal of attention as potential agents for forestalling age-related free radical-based diseases (Halliwell, 2001; Harman, 2002; Reiter et al.,
2003). The information on the scavenging actions of antioxidants may be particularly important for the aged where free radical-mediated diseases are numerous and, furthermore, the aging process itself is believed, in part, to be a result of the persistent accumulation of molecular debris resulting from the unending mutilation by free radicals (Harman, 1998; 1999; Fossel, 2002).

In the last 10 years, a vast amount of published literature has been amassed that provides unequivocal documentation that, in vivo, melatonin has the capability of diminishing destruction of DNA, proteins and lipids that are a result of their reactions with ROS and RNS. The number of publications regarding these actions in non-human mammals is so massive that it is not possible to discuss these findings in the current report and the reader is referred to other sources for this information (Reiter et al., 2000a; 2002a; 2003; Cardinali et al., 2003; Cheung, 2003). Rather, summarized below are some of the studies in which melatonin has been used to combat free radical damage in humans.

Based on a substantial amount of data documenting melatonin's ability to reduce neural damage in models of Alzheimer's disease (AD) (Pappolla et al., 2000; 2003), several groups have administered melatonin to individuals diagnosed with this neurodegenerative condition in attempt to ameliorate disease symptoms. The first of these reports appeared in 1998 when Brusco et al. (1998a) showed that giving one of a pair of monozygotic twins (both with AD) $6 \mathrm{mg}$ melatonin daily for 36 months significantly delayed the progression of the disease and reduced the degree of brain atrophy (as estimated by nuclear magnetic resonance imaging of the CNS). Melatonin is known to readily cross the blood-brain barrier and neuronal loss in $\mathrm{AD}$ is believed to be a consequence of free radical-mediated apoptosis. Thus, in this study melatonin's antioxidant functions presumably helped preserve neurons from mutilation and death. Using be- 
havioral endpoints, several studies have also shown that melatonin may also improve locomotor activity and affect in $\mathrm{AD}$ patients (Brusco et al., 1998b; Cohen-Mansfield et al., 2000). In addition to the report that recently appeared (Asayama et al., 2003), more extensive investigations that are double-blind and placebo-controlled are needed. There is certainly ample experimental evidence to justify treating $\mathrm{AD}$ patients and elderly with related degenerative diseases of the CNS with melatonin (Reiter et al., 2000a; Cheung, 2003). Also, there is virtually no acute or chronic toxicity of melatonin (Jahnke et al., 1999; Jan et al., 2000; Seabra et al., 2000) which should encourage its long-term use in individuals with age-related neurodegenerative diseases.

Melatonin has proven useful as a treatment for septic shock in premature newborns as well (Gitto et al., 2001b). Sepsis is a serious condition and occurs in 1-10 cases per 1000 births with even higher rates than this in low-birth-weight neonates. The mortality rates in newborns who become septic can be as high as $50 \%$. Sepsis culminates in multiple organ failure and death with the tissue damaged generally believed to be due, at least in part, to excessive free radical generation. Since melatonin had been shown to be an effective treatment for bacterial lipopolysaccharide (Sewerynek et al., 1995), which causes multiple organ failure in rats, Gitto and co-workers (2001b) tested its efficacy as a treatment for sepsis in human premature newborns.

Twenty newborns judged to be septic were randomly divided into 2 groups of 10 infants each; all were given conventional antibiotic therapy but 10 were also supplemented with 2 doses of $10 \mathrm{mg}$ oral melatonin (separated by a $1 \mathrm{~h}$ interval). Within $1 \mathrm{~h}$ and also at $4 \mathrm{~h}$ after melatonin administration, the levels of lipid peroxidation products in the serum were already depressed relative to those in non-melatonin treated children. Additionally, over the next $72 \mathrm{~h}$ all clinical parameters improved sig- nificantly more quickly in the children given melatonin. As is usual, 3 or 10 neonates not treated with melatonin died; conversely, due to their more rapid recovery all of the melatonin treated children survived. Gitto et al. (2001b) attributed the beneficial actions of melatonin in this study to the antioxidant properties of the indoleamine although there may have been other yet to be defined actions which permitted the children to exhibit a more rapid recovery from sepsis. Regardless of the mechanisms of protection by melatonin, the outcome of this study seemingly justifies the use of melatonin in the treatment of this serious condition not only in children but in adults as well.

A variety of conditions in neonates is associated with elevated oxidative stress (Gitto et al., 2002). Considering the high efficacy and low toxicity of melatonin in these conditions and stimulated by the successful use of melatonin as described above (Gitto et al., 2001b), Fulia and co-workers (2001) used the indoleamine to treat newborns who were suffering from transient asphyxia; free radical damage has been implicated in the pathophysiology of neonatal asphyxia. Twenty newborns with perinatal asphyxia diagnosed within the first $6 \mathrm{~h}$ of life were studied, 10 of who were given $80 \mathrm{mg}$ melatonin orally. In the asphyxiated neonates given melatonin, serum levels of malondialdehyde (a lipid peroxidation product) and nitrite/nitrate concentrations were significantly reduced relative to those in the non-melatonin treated, asphyxiated children. Likewise, the clinical improvement was faster in the neonates given melatonin and all of these individuals survived; conversely, 3 of 10 non-melatonin-treated, asphyxiated children died (Fulia et al., 2001).

Reactive oxygen species have also been implicated in the pathogenesis of respiratory distress syndrome (RDS) and its complications (Gitto et al., 2001c). Given this, the rationale for treating children with RDS (grade III or IV) with melatonin is clear. In this case, 40 RDS newborns were given melatonin (100 
mg given intravenously over a 2 day period) and 34 were provided conventional therapy only. At 24 and $72 \mathrm{~h}$ and at 7 days after melatonin administration, serum interleukin (IL)-6, IL-8, tumor necrosis factor alpha (TNF- $\alpha$ ) and nitrite/nitrate levels were significantly lower in the melatonin-treated RDS neonates relative to the newborns suffering with RDS but given conventional treatment (Gitto et al., 2004). Clearly, melatonin improved the outcome of the RDS afflicted newborns by reducing oxidative and inflammatory parameters associated with this condition.

Melatonin has also been tested as an agent to reduce oxidative stress in adult humans subjected to cardiopulmonary bypass surgery (CPB) (Ochoa et al., 2003). Melatonin when given in advance of surgery onset reduced the degree of lipid peroxidation products in erythrocyte membranes of blood collected at various intervals after the onset of the operation. Another index of the breakdown of membrane lipids also documented the protective effect of melatonin. Thus, the increase in red blood cell membrane rigidity (decreased membrane fluidity) was also attenuated in the CPB individuals treated with melatonin. An increased membrane rigidity correlates positively with augmented levels of products of lipid peroxidation (Garcia et al., 1999).

\section{CONCLUDING REMARKS}

Since the discovery of melatonin as an antioxidant in 1993 (Tan et al., 1993), there has been an burgeoning number of reports documenting this action under an almost unlimited number of conditions, many of which have direct clinical relevance. Thus, melatonin has been shown to reduce the toxicity of drugs and in some cases improve their efficacy (Reiter et al., 2002c), to reduce the severity and degree of tissue damage following ischemia/reperfusion in the brain (Cheung, 2003) and other organs, to prevent degenera- tive changes in the CNS in models of Alzheimer's (Pappolla et al., 2000) and Parkinson's disease (Antolin et al., 2002), to reduce free radical damage to DNA which may lead to cancer (Reiter et al., 1998), and many other situations too numerous to mention in this brief report.

A major unresolved issue, as already mentioned above, relates to the significance of the various actions of melatonin that function in reduction of oxidative stress. At this point, it is unknown which of the multiple actions of melatonin, i.e., whether free radical scavenging, stimulation of antioxidative enzymes, increasing the efficacy of mitochondrial ETC and reducing electron leakage, improving the efficiency of other antioxidants, etc., are most important in contributing to its high efficacy. It is also likely that both receptor-independent and receptor-dependent actions of melatonin participate in its function as an antioxidant (Tan et al., 2003a). Its successful use in human conditions where excessive free radical generation occurs, however, should encourage its continued use in the treatment of other disease processes, and there seem to be many, where oxidative stress is a component.

\section{R E F E R E N C E S}

Absi E, Ayala A, Machado A, Prado J. (2000) Protective effect of melatonin against the 1-methyl-4-phenylpyridinium-induced inhibition of complex I of the mitochondrial respiratory chain. J Pineal Res.; 29: 40-7.

Acuña-Castroviejo D, Escames G, Carozo A, Leon J, Khaldy H, Reiter RJ. (2002) Melatonin, mitochondrial homeostasis and mitochondrial-related diseases. Curr Topics Med Chem.; 2: 133-52.

Allegra M, Reiter RJ, Tan DX, Gentile C, Tesoriere L, Livrea MA. (2003) The chemistry of melatonin's interaction with reactive species. J Pineal Res.; 34: 1-10.

Antolin I, Mayo JC, Sainz RM, del Brio ML, Herrera F, Martin V, Rodriquez C. (2002) 
Protective effect of melatonin in a chronic experimental model of Parkinson's disease. Brain Res.; 943: 163-73.

Antunes F, Barclay LRC, Ingold KU, King M, Norris JO, Sciano JL, Xi F.

(1999) On the antioxidant activity of melatonin. Free Radic Biol Med.; 26: $117-28$.

Asayama K, Yamadera H, Ito T, Suzuki H, Kudo Y, Endo S. (2003) Double blind study of melatonin effects on the sleep-wake rhythm, cognitive and non-cognitive functions in Alzheimer type dementia. J Nippon Med Sch.; 70: 334-41.

Bandyopadhyay D, Bandyopadhyay A, Das PK, Reiter RJ. (2002) Melatonin protects against gastric ulceration and increases the efficacy of ranitidine and omeprazole in reducing gastric damage. J Pineal Res.; 33: 1-7.

Barlow-Walden LR, Reiter RJ, Abe M, Pablos M, Menendez-Pelaez A, Chen LD, Poeggeler B. (1995) Melatonin stimulates brain glutathione peroxidase activity. Neurochem Int.; 26: 447-52.

Blanchard B, Pompon D, Ducroq C. (2000) Nitrosation of melatonin by nitric oxide and peroxynitrite. J Pineal Res.; 29: 184-92.

Blask DE, Sauer LA, Dauchy RT. (2002) Melatonin as a chronobiotic/anticancer agent: Cellular, biochemical, and molecular mechanisms of action and their implications for circadian-based therapy. Curr Topics Med Chem.; 2: 113-32.

Brömme HJ, Mörke W, Peschke E. (2002) Transformation of barbituric acid into alloxan by hydroxyl radicals: interaction with melatonin and other hydroxyl radical scavengers. J Pineal Res.; 33: 239-47.

Brusco LI, Marquez M, Cardinali DP. (1998a) Monozygotic twins with Alzheimer's disease treated with melatonin: Case report. $J P i$ neal Res.; 25: 260-3.

Brusco LI, Marquez M, Cardinali DP. (1998b) Melatonin treatment stabilizes chronobiological and cognitive symptoms in Alzhei- mer's disease. Neuroendocrinol Lett.; 19: 111-16.

Burkhardt S, Poeggeler B, Tan DX, Rosner C, Gruetzner T, Nitzki F, Schoenke M, Thuermann S, Reiter RJ, Hardeland R. (2001) Oxidation products formed from melatonin in various radical-generating systems. In Actions and redox properties of melatonin in various radical-generating systems. Hardeland R, ed, pp 9-22. Cuvillier, Göttingen.

Carampin P, Rosan S, Dalzoppo D, Zagotto G, Zatla P. (2003) Some biochemical properties of melatonin and the characterization of a relevant metabolite arising from its interaction with $\mathrm{H}_{2} \mathrm{O}_{2}$. J Pineal Res.; 34: 134-42.

Cardinali DP, Ladizesky MG, Boggio V, Cutrera RA, Mautalen C. (2003) Melatonin effects on bone: Experimental facts and clinical perspectives. J Pineal Res.; 34: 81-7.

Cheung RTF. (2003) The utility of melatonin in reducing cerebral damage resulting from ischemia and reperfusion. J Pineal Res.; 34: 153-60.

Cohen-Mansfield JS, Garfinkel D, Lipton S. (2000) Melatonin for treatment of sun downing in elderly persons with dementia a preliminary study. Arch Gerontol Geriatrics.; 35: 65-71.

Cuzzocrea S, Reiter RJ. (2002) Pharmacological actions of melatonin in acute and chronic inflammation. Curr Topics Med Chem.; 2: 153-66.

De Almeida EA, Martinez GR, Klitzke CF, de Medeiros MHG, Di Mascio P. (2003) Oxidation of melatonin by singlet molecular oxygen $\left(\mathrm{O}_{2}\left({ }^{1} \Delta \mathrm{g}\right)\right)$ produces $N^{1}$-acetyl- $N^{2}$-formyl5-methoxykynuramine. J Pineal Res.; 35: $131-7$.

Decker JF, Quay WB. (1982) Stimulatory effects of melatonin on ependymal epithelium of choroid plexuses in golden hamsters. $J$ Neural Trasnm.; 55: 53-67.

Dellegar SM, Murphy SA, Boune AE. (1999) Identification of factors affecting the rate of deactivation of hypochlorous acid by 
melatonin. Biochem Biophys Res Commun.; 257: 431-39.

Fossel M. (2002) Cell senescence in human aging and disease. Ann NY Acad Sci.; 979: $14-23$

Fowler G, Daroszewska M, Ingold KU. (2003) Melatonin does not directly scavenge hydrogen peroxide. Free Radic Biol Med.; 34: $77-83$.

Fulia F, Gitto E, Cuzzocrea S, Reiter RJ, Dugo L, Gitto P, Barberi S, Cordaro S, Barber I. (2001) Increased levels of malondialdehyde and nitrite/nitrate in the blood of asphyxiated newborns: Reduction by melatonin. $J$ Pineal Res.; 31: 343-9.

Garcia JJ, Reiter RJ, Pie J, Ortiz GG, Cabrera J, Sainz RM, Acuña-Castroviejo D. (1999)

Role of pinoline and melatonin in stabilizing hepatic microsomal membranes against oxidative stress. J Bioenerg Biomembr.; 31: 601-16.

Gitto E, Tan DX, Reiter RJ, Karbownik M, Manchester LC, Cuzzocrea S, Fulia F, Barberi I. (2001a) Individual and synergistic actions of melatonin: Studies with vitamin $\mathrm{E}$, vitamin $\mathrm{C}$, glutathione and desferoxamine in liver homogenates. J Pharm Pharmacol.; 53: 1393-401.

Gitto E, Karbownik M, Reiter RJ, Tan DX, Cuzzocrea S, Chiurazzi P, Cordaro S, Corona G, Trimarchi G, Barberi I. (2001b) Effects of melatonin treatment in septic newborns. Pediat Res.; 50: 756-60.

Gitto E, Reiter RJ, Karbownik M, Tan DX, Barberi I. (2001c) Respiratory distress syndrome in the newborn: Role of oxidative stress. Inten Care Med.; 27: 1116-23.

Gitto E, Reiter RJ, Karbownik M, Tan DX, Gitto P, Barberi S, Barberi I. (2002) Causes of oxidative stress in the pre- and postnatal period. Biol Neonate.; 81: 146-57.

Gitto E, Reiter RJ, Cordaro SP, La Rosa M, Chiurazzi P, Trimarchi G, Gitto P, Calabro MP, Barberi I. (2004) Oxidative and respiratory parameters in respiratory distress syndrome of preterm newborns: Beneficial ef- fects of melatonin. Am J Perinatol.; in press.

Guerrero JM, Reiter RJ. (2002) Melatonin-immune system relationships. Curr Topics Med Chem.; 2: 167-80.

Halliwell B. (2001) Free radical reactions in human disease. In Environmental stressors in health and disease. Fuchs J, Packer L, eds, pp 1-16. Marcel Dekker, New York.

Hara M, Yoshida M, Nishijima H, Yokosuka M, Iigo M, Ohtani-Kaneko R, Shimada A, Hasegawa T, Akama Y, Hirata K. (2001) Melatonin, a pineal secretory product with antioxidant properties, protects against cisplatin-induced nephrotoxicity in rats. $J$ Pineal Res.; 30: 129-38.

Hardeland R, Reiter RJ, Poeggeler B, Tan DX. (1993) The significance of the metabolism of the neurohormone melatonin: Antioxidative protection and formation of bioactive substances. Neurosci Biobehav Rev.; 17: 347-57.

Hardeland R, Balzer I, Poeggeler B, Fuhrberg B, Uria H, Bahrmann G, Wolf R, Meyer TJ, Reiter RJ. (1995) On the primary functions of melatonin in evolution: mediation of photoperiodic signals in unicell, photoxidation, and scavenging of free radicals. J Pineal Res.; 18: 104-11.

Harman D. (1998) Aging: Phenomenon and theories. Ann NY Acad Sci.; 850: 1-7.

Harman D. (1999) Free radical theory of aging: Increasing the average life expectancy at birth and the maximum life span. $J$ Anti-Aging Med.; 2: 199-208.

Harman D. (2002) Alzheimer's disease: Role of aging in pathogenesis. Ann NY Acad Sci.; 959: 384-95.

Jahnke G, Marr M, Myers C. (1999) Maternal and developmental toxicity evaluation of melatonin administration orally to pregnant Sprague-Dawley rats. Toxicol Res.; 50: 271-9.

Jan JE, Hamilton D, Seward N, Fast DK, Freeman RD, Landon M. (2000) Clinical trials of controlled-release melatonin in children with sleep-wake disorders. J Pineal Res.; 29: 34-9. 
Kennaway DJ, Wright H. (2002) Melatonin and circadian rhythms. Curr Topics Med Chem.; 2: 199-209

Kotler ML, Rodriquez C, Sainz RM, Antolin I, Menendez-Pelaez A. (1998) Melatonin increases gene expression for antioxidant enzymes in rat brain cortex. J Pineal Res.; 24: 83-9.

Li XJ, Gu J, Lu SD, Sun FY. (2002) Melatonin attenuates MPTP-induced dopaminergic neuronal injury associated with scavenging hydroxyl radical. J Pineal Res.; 32: 47-52.

Livrea MA, Tesoriere L, D’Arpa D, Morreale M. (1997) Reaction of melatonin with lipoperoxyl radicals in phospholipid bilayers. Free Radic Biol Med.; 23: 706-11.

Lopez-Burillo S, Tan DX, Rodriquez-Gallego V, Manchester LC, Mayo JC, Sainz RM, Reiter RJ. (2003) Melatonin and its derivatives cyclic 3-hydroxymelatonin, $N^{1}$-acetyl- $N^{2}$-formyl-5-methoxykynuramine and 6-hydroxymelatonin reduce oxidative damage induced by Fenton reagents. $J$ Pineal Res.; 34: $178-84$.

Mahal HS, Sharma HS, Mukherjee T. (1999) Antioxidant properties of melatonin: A pulse radiolysis study. Free Radic Biol Med.; 26: 577-65.

Marshall KA, Reiter RJ, Poeggeler B, Aruoma OI, Halliwell B. (1996) Evaluation of the antioxidant activity of melatonin in vitro. Free Radic Biol Med.; 21: 307-15.

Martin M, Macias M, Escames G, Reiter RJ, Agapito MT, Ortiz GG, Acuña-Castroviejo D. (2000a) Melatonin-induced increased activity of the respiratory chain complexes I and IV can prevent mitochondrial damage induced by ruthenium red in vitro. $J$ Pineal Res.; 28: 242-8.

Martin M, Macias M, Escames G, Leon J, Acuña-Castroviejo D. (2000b) Melatonin but not vitamins $\mathrm{C}$ and $\mathrm{E}$ maintains glutathione homeostasis in $t$-butylhydroperoxide induced mitochondrial oxidative stress. FASEB J.; 14: 1677-9.

Martin M, Macias M, Leon J, Escames G, Khaldy H, Acuña-Castroviejo D. (2001)
Melatonin increases the activity of oxidative phosphorylation enzymes and the production of ATP in rat brain and liver mitochondria. Int J Biochem Cell Biol.; 1212: 1-10.

Matuszak A, Reszka KJ, Chignell CF. (1997) Reaction of melatonin and related indoles with hydroxyl radicals: EPR and spin trapping investigations. Free Radic Biol Med.; 23: $367-72$

Mayo JC, Sainz RM, Antolin I, Herrera F, Martin V, Rodriquez C. (2002) Melatonin regulation of antioxidant enzyme gene expression. Cell Mol Life Sci.; 59: 1706-13.

Mayo JC, Tan DX, Sainz RM, Lopez-Burillo S, Reiter RJ. (2003) Oxidative damage to catalase induced by peroxyl radicals: Functional protection by melatonin and other antioxidants. Free Radic Res.; 37: 543-53.

Milczarek R, Klimek J, Zelewski L. (2000) Melatonin inhibits NADPH-dependent lipid peroxidation in human placental mitochondria. Horm Metab Res.; 32: 84-5.

Naidu PS, Singh A, Kaur P, Sandhir R, Kulkawi SK. (2003) Possible mechanism of action of melatonin attenuation of haloperidol-induced orofacial dyskinesia. Pharmacol Biochem Behav.; 74: 641-8.

Noda Y, Mori A, Liburty R, Packer L. (1999) Melatonin and its precursors scavenge nitric oxide. J Pineal Res.; 27: 159-64.

Ochoa JJ, Vilchez MJ, Palacios MA, Garcia JJ, Reiter RJ, Munoz-Hoyos A. (2003) Melatonin protects against lipid peroxidation and membrane rigidity in erythrocytes from patients undergoing cardiopulmonary bypass surgery. J Pineal Res.; 35: 104-8.

Okatani Y, Wakatsuki A, Kaneda C. (2000) Melatonin increases activities of glutathione peroxidase and superoxide dismutase in fetal rat brain. J Pineal Res.; 28: 89-96.

Okatani Y, Wakatsuki A, Shinohara K, Kaneda C, Fukaya T. (2001) Melatonin stimulates glutathione peroxidase activity in human chorion. J Pineal Res.; 30: 199-205.

Okatani Y, Wakatsuki A, Reiter RJ. (2002a) Melatonin protects hepatic mitochondrial 
chain activity in senescence-accelerated mice. J Pineal Res.; 23: 143-8.

Okatani Y, Wakatsuki A, Reiter RJ, Miyahara Y. (2002b) Hepatic mitochondrial dysfunction in senescence-accelerated mice: Correction by long-term, orally administered physiological levels of melatonin. J Pineal Res.; 33: $127-33$.

Okatani Y, Wakatsuki A, Reiter RJ, Miyahara Y. (2003a) Acutely administered melatonin restores hepatic mitochondrial physiology in old mice. Int J Biochem Cell Biol.; 35: $367-75$.

Okatani Y, Wakatsuki A, Reiter RJ, Enzan H, Miyahara Y. (2003b) Protective effective of melatonin against mitochondrial injury induced by ischemia and reperfusion of rat liver. Eur J Pharmacol.; 469: 145-52.

Pablos MI, Agapito MT, Gutierrez R, Recio JM, Reiter RJ, Barlow-Walden LF, Acuña-Castroviejo D, Menendez-Pelaez A. (1995) Melatonin stimulates the activity of the detoxifying enzyme glutathione peroxidase in several tissues of chicks. $J P i$ neal Res.; 19: 111-5.

Pablos MI, Guerrero JM, Ortiz GG, Agapito MT, Reiter RJ. (1997) Both melatonin and a putative receptor agonist CGP 52608 stimulate glutathione peroxidase and glutathione reductase activities in mouse brain in vivo. Neuroendocrinol Lett.; 18: 49-58.

Pablos MI, Reiter RJ, Ortiz GG, Guerrero JM, Agapito MT, Chuang JI, Sewerynek E. (1998) Rhythms of glutathione peroxidase and glutathione reductase in brain of chick and their inhibition by light. Neurochem Int.; 32: 69-75.

Pappolla MA, Chyan YJ, Poeggeler B, Frangione B, Wilson G, Chiso J, Reiter RJ. (2000) An assessment of the antioxidant and antiamyloidogenic properties of melatonin: Implications for Alzheimer's disease. $J \mathrm{Neu}$ ral Transm.; 107: 203-31.

Pappolla MA, Reiter RJ, Bryant-Thomas TK, Poeggeler B. (2003) Oxidative mediated neurodegeneration in Alzheimer's disease: Melatonin and related antioxidants as neuroprotective agents. Curr Med Chem.; 3: 233-43.

Pieri C, Marra M, Moroni F, Recchioni R, Marcheselli F. (1994) Melatonin: A peroxyl radical scavenger more effective than vitamin E. Life Sci.; 55: 271-76.

Pieri C, Moroni M, Marcheselli F, Recchioni R. (1995) Melatonin is an efficient antioxidant. Arch Gerontol Geriatr.; 20: 159-65.

Pierrefiche G, Laborit H. (1995) Oxygen radicals, melatonin and aging. Exp Gerontol.; 30: $213-27$.

Poeggeler B, Saarela S, Reiter RJ, Tan DX, Chen LD, Manchester LC, Barlow-Walden L. (1994) Melatonin - a highly potent endogenous scavenger and electron donor: New aspects of the oxidation chemistry of this indole assessed in vitro. Ann NY Acad Sci.; 738: $719-20$.

Poeggeler B, Reiter RJ, Hardeland R, Tan DX, Barlow-Walden LR. (1996) Melatonin and structurally related endogenous indoles act as potent electron donors and radical scavengers in vitro. Redox Rep.; 2: 179-84.

Poeggeler B, Thuermann S, Dose A, Schoenke M, Burkhardt S, Hardeland R. (2002) Melatonin's unique scavenging properties roles of its functional substituents as revealed by a comparison with its structural analogues. J Pineal Res.; 33: 20-30.

Poon AMS, Pang SF. (1992) 2[ ${ }^{125}$ I]iodomelatonin binding sites in spleens of guinea pigs. Life Sci.; 50: 1719-26.

Qi W, Reiter RJ, Tan DX, Manchester LC, Siu AW, Garcia JJ. (2000) Increased levels of oxidatively damaged DNA induced by chromium(III) and $\mathrm{H}_{2} \mathrm{O}_{2}$ : Protection by melatonin and related indoles. $J$ Pineal Res.; 29: 54-61.

Reiter RJ. (1980) The pineal and its hormones in the control of reproduction in mammals. Endocrine Rev.; 1: 109-31.

Reiter RJ. (1991) Pineal melatonin: Cell biology of its synthesis and of its physiological interactions. Endocrine Rev.; 12: 151-80. 
Reiter RJ. (1998) Oxidative damage in the central nervous system: Protection by melatonin. Prog Neurobiol.; 56: 359-84.

Reiter RJ, Tan DX. (2003) Melatonin: A novel protective agent against oxidative injury of the ischemic/reperfused heart. Cardiovasc Res.; 58: 10-9.

Reiter RJ, Tan DX, Kim SJ, Qi W. (1998). Melatonin as a pharmacological agent against damage to lipids and DNA. Proc West Pharmacol Soc.; 41: 229-36.

Reiter RJ, Cabrera J, Sainz RM, Mayo JC, Manchester LC, Tan DX. (2000a) Melatonin as a pharmacological agent against neuronal loss in experimental models of Huntington's disease, Alzheimer's disease and Parkinsonism. Ann NY Acad Sci.; 899: 471-85.

Reiter RJ, Tan DX, Acuña-Castroviejo D, Burkhardt S, Karbownik M. (2000b) Melatonin: Mechanisms and actions as an antioxidant. Curr Topics Biophys.; 24: $171-83$

Reiter RJ, Tan DX, Osuna C, Gitto E. (2000c) Actions of melatonin in the reduction of oxidative stress: A review. J Biomed Res.; 7: 444-58.

Reiter RJ, Tan DX, Manchester LC, Qi W. (2001) Biochemical reactivity of melatonin with reactive oxygen and nitrogen species: A review of the evidence. Cell Biochem Biophys.; 34: 237-56.

Reiter RJ, Tan DX, Allegra M. (2002a) Melatonin: Reducing molecular pathology and dysfunction due to free radicals and associated reactants. Neuroendocrinol Lett.; 23: $3-8$.

Reiter RJ, Tan DX, Manchester LC, Calvo JR. (2002b) Antioxidative capacity of melatonin. In Handbook of antioxidants, 2nd edn. Cadenas E, Packer L, ed, pp 565-613. Marcel Dekker, New York.

Reiter RJ, Tan DX, Sainz RM, Mayo JC. (2002c) Melatonin: Reducing the toxicity and increasing the efficacy of drugs. $J$ Pharm Pharmacol.; 54: 299-321.
Reiter RJ, Sainz RM, Lopez-Burillo S, Mayo JC, Manchester LC, Tan DX. (2003) Melatonin ameliorates neurological damage and neurophysiological deficits in experimental models of stroke. Ann NY Acad Sci.; 993: $35-47$.

Ressmeyer AR, Mayo JC, Zelosko V, Sainz RM, Tan DX, Poeggeler B, Antolin I, Reiter RJ, Hardeland R. (2003) Antioxidant properties of the melatonin metabolite $\mathrm{N}$-acetyl-5-methoxykynuramine (AMK): Scavenging of free radicals and prevention of protein destruction. Redox Rept.; 8: 205-13.

Roberts JE, Hu DN, Martinez L. (2000) Photophysical studies on melatonin and its receptor agonists. J Pineal Res.; 29: 94-9.

Rodriquez C, Mayo JC, Sainz RM, Antolin I, Herrera F, Martin V, Reiter RJ. (2004) Regulation of antioxidant enzymes: A significant role for melatonin. J Pineal Res.; in press.

Rozov SV, Filatova EV, Orlov AA, Volkova AV, Zhloba AA, Blashko EL, Pozdeyev NV. (2003) $N^{1}$-Acetyl- $N^{2}$-formyl-5-methoxykynuramine is a product of melatonin oxidation in rats. $J$ Pineal Res.; 35: 245-50.

Scaiano JC. (1995) Exploratory laser flash photolysis study of free radical reactions and magnetic field effects in melatonin chemistry. J Pineal Res.; 19: 189-95.

Seabra M de LV, Bignotto M, Pinto LR Jr, Tufik S. (2000) Randomized double blind clinical trial, controlled with placebo, of the toxicology of chronic melatonin treatment. J Pineal Res.; 29: 193-200.

Sewerynek E, Melchiorri D, Reiter RJ, Ortiz GG, Lewinski A. (1995) Lipopolysaccharide-induced hepatotoxicity is inhibited by the antioxidant melatonin. Eur $J$ Pharmacol.; 293: 327-34.

Stasica P, Paneth P, Rosiak JM. (2000) Hydroxyl radical reaction with melatonin molecule: A computational study. J Pineal Res.; 29: 125-7.

Tan DX, Chen LD, Poeggeler B, Manchester LC, Reiter RJ. (1993) Melatonin: A potent, endogenous hydroxyl radical scavenger. Endocrine J.; 1: 57-60. 
Tan DX, Manchester LC, Reiter RJ, Plummer BF, Hardies LJ, Weintraub ST, Vijayalaxmi, Shepard AMM. (1998) A novel melatonin metabolite, cyclic 3-hydroxymelatonin: A biomarker of in vivo hydroxyl radical generation. Biochem Biophys Res Commun.; 253: 614-20.

Tan DX, Manchester LC, Reiter RJ, Plummer BL, Limson J, Weintraub ST, Qi W. (2000) Melatonin directly scavenges hydrogen peroxide: A potentially new metabolic pathway of melatonin biotransformation. Free Radic Biol Med.; 29: 1177-85.

Tan DX, Manchester LC, Burkhardt S, Sainz RM, Mayo JC, Kohen R, Shohami E, Huo YS, Hardeland R, Reiter RJ. (2001) $N^{1}$-Acetyl- $N^{2}$-formyl-5-methoxykynuramine, a biogenic amine and melatonin metabolite, functions as a potent antioxidant. FASEB J.; 15: 2294-6.

Tan DX, Reiter RJ, Manchester LC, Yan MT, El-Sawi M, Sainz RM, Mayo JC, Kohen R, Allegra M, Hardeland R. (2002) Chemical and physical properties and potential mechanisms: Melatonin as a broad-spectrum antioxidant and free radical scavenger. Curr Topics Med Chem.; 2: 181-98.

Tan DX, Manchester LC, Hardeland R, Lopez-Burillo S, Mayo JC, Sainz RM, Reiter RJ. (2003a) Melatonin: A hormone, a tissue factor, an autocoid, a paracoid and an antioxidant vitamin. J Pineal Res.; 34: 75-8.

Tan DX, Hardeland R, Manchester LC, Poeggeler B, Lopez-Burillo S, Mayo JC, Sainz RM, Reiter RJ. (2003b) Mechanistic and comparative studies of melatonin and classic antioxidants in terms of their interactions with the ABTS cation radical. J Pineal Res.; 34: 249-59.

Turjanski AG, Chaia Z, Rosenstein RE, Estrin DA, Doctorovich F, Piro O. (2000a)
N-Nitrosomelatonin. Acta Crystallogr C.; 56: 682-3.

Turjanski AG, Leonik F, Rosenstein RE, Estrin DA, Doctorovich F. (2000b) Scavenging of NO by melatonin. J Am Chem Soc.; 122: 10468-9.

Turjanski AG, Saenz DA, Doctorovich F, Estrin DA, Rosenstein RE. (2000c) Nitrosation of melatonin by nitric oxide: A computational study. J Pineal Res.; 31: 97-101.

Urata Y, Honma S, Goto S, Todoroki S, Ueda T, Cho S, Honma K, Kondo T. (1999) Melatonin induces gamma-glutamylcysteine synthetase mediated by activator protein- 1 in human vascular endothelial cells. Free Radic Biol Med.; 27: 838-47.

Wakatsuki A, Okatani Y, Shivohara K, Ikenoue N, Fukaya T. (2001) Melatonin protects against ischemia/reperfusion-induced oxidative damage to mitochondria in fetal rat brain. J Pineal Res.; 31: 167-72.

Yamamoto HA, Yang HW. (1996) Preventive effect of melatonin against cyanide-induced seizures and lipid peroxidation in mice. Neurosci Lett.; 207: 89-92.

Zang LY, Cosma G, Gardner H, Vallynathan V. (1998) Scavenging of reactive oxygen species by melatonin. Biochim Biophys Acta.; 1425: 467-77.

Zhang H, Squadrito GI, Pryor WA. (1998) The reaction of melatonin with peroxynitrite: Formation of melatonin radical cation and absence of stable nitrated products.

Biochem Biophys Res Commun.; 25: 83-7.

Zhang H, Squadrito GL, Uppu R, Pryor WA. (1999) Reaction of peroxynitrite with melatonin: A mechanistic study. Chem Res Toxicol.; 12: 516-34. 